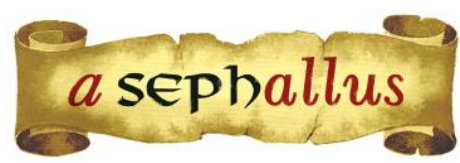

Revista aSEPHallus de Orientação Lacaniana

Núcleo Sephora de Pesquisa sobre o Moderno e o Contemporâneo

ISSN $1809-709$ X

\begin{abstract}
Vulnerabilidade social e as modalidades do desamparo em Freud: desamparo estrutural, radical e generalizado
\end{abstract}

Andréa Máris Campos Guerra Orcid: 0000-0001-5327-0694

Pós-Doutorado em andamento na Université Paris 8 (Paris, França)

Doutora em Teoria Psicanalítica pela Universidade Federal do Rio de Janeiro / UFRJ (Rio de Janeiro, Br) Professora adjunta do Departamento e do Programa de Pós-Graduação em Psicologia da Universidade

Federal de Minas Gerais - UFMG (Belo Horizonte, Minas Gerais, Brasil)

Bolsista de Produtividade em Pesquisa do CNPq - Nível 2, Financiamento CAPES

E-mail: andreamcguerra@gmail.com

Mônica Eulália da Silva Januzzi Orcid: 0000-0003-0788-9968

Pós-doutoranda pela Universidade Federal de Minas Gerais / UFMG (Belo Horizonte, Minas Gerais, Br)

Doutora pela PUC-Minas (Belo Horizonte, MG, Br)

Professora na Faculdade Pitágoras (Betim, Minas Gerais, Brasil)

E-mail: monicaesilva@yahoo.com.br

\begin{abstract}
Resumo: O artigo interroga o termo desamparo em Freud a partir da noção de perigo pulsional, com a finalidade de situar sua especificidade teórico-conceitual, enquanto paradigma possível para estabelecer um diálogo com o campo das disciplinas sociais. A partir de algumas contribuições da psicanálise lacaniana a noção de desamparo em Freud, enquanto perigo pulsional, é colocada a prova a partir de três modalizações do termo, extraídas das citações encontradas na obra freudiana, isto é: o desamparo estrutural, radical e generalizado. A análise dos termos se deu a partir da proposta de análise estrutural de Lacan na distinção entre sentido e significação. 0 artigo mostrou ser possível o diálogo interdisciplinar com o campo das teorias sociais considerando o termo desamparo em Freud como paradigma da vulnerabilidade em psicanálise.
\end{abstract}

Palavras-chave: Vulnerabilidade; desamparo; psicanálise.

Vulnérabilité sociale et formes d'impuissance chez Freud: impuissance structurelle, radicale et généralisée L'article investigue l'utilisation du terme « 'impuissance » chez Freud à partir de la notion de danger pulsionnel, dans le but de situer sa spécificité théorico-conceptuelle, comme paradigme possible pour établir un dialogue avec le champ des disciplines sociales. A partir de quelques apports de la psychanalyse lacanienne, la notion d'impuissance chez Freud, comme danger pulsionnel, est mise à l'épreuve a partir de trois modalisations du terme, extraites des citations retrouvées dans l'œuvre freudienne, à savoir: l'impuissance structurelle, radicale et généralisée. L'analyse des termes était basée sur la proposition d'analyse structurale de Lacan dans la distinction entre sens et signification. L'article a montré qu'un dialogue interdisciplinaire avec le champ des théories sociales est possible en considérant le concept d'impuissance chez Freud comme un paradigme de vulnérabilité en psychanalyse.

Mots clés: vulnérabilité; impuissance; psychanalyse.

Social vulnerability and the forms of helplessness in Freud: structural, radical and generalized helplessness: The article investigates Freud's use of the term helplessness the notion of instinctual danger, in order to situate his theoretical-conceptual specificity, as a possible paradigm for establishing a dialogue with the field of social disciplines. Based on some contributions from Lacanian psychoanalysis, the notion of helplessness in Freud, as a drive danger, is put to the test based on three modalizations of the term, extracted from the quotations found in Freud's work, namely: structural, radical and generalized helplessness. The analysis of the terms was based on Lacan's structural analysis proposal in the distinction between sense and signification. The 
article showed that an interdisciplinary dialogue with the field of social theories is possible considering the term helplessness in Freud as a paradigm of vulnerability in psychoanalysis.

Keywords: Vulnerability; helplessness; psychoanalysis. 


\title{
Vulnerabilidade social e as modalidades do desamparo em Freud: desamparo estrutural, radical e generalizado
}

\author{
Andréa Máris Campos Guerra \& Mônica Eulália da Silva Januzzi
}

\section{Introdução}

Em pesquisa desenvolvida no Núcleo de Psicanálise e Laço Social no Contemporâneo, (PSILACS), na UFMG, o estudo de jovens em situação de vulnerabilidade nos levou a traçar dois eixos de investigação: uma análise teórica-conceitual dos termos ação específica e desamparo na obra de Freud e o estudo clínico de quatro casos. O trabalho em questão consiste no segundo produto desenvolvido no eixo teórico-conceitual da pesquisa, tendo em vista que o primeiro se referiu ao estatuto do termo ação específica em Freud. $O$ artigo que ora apresentamos interroga o estatuto do termo desamparo na obra freudiana, já que, no diálogo interdisciplinar com outros campos, é importante se ter claro de que modo a psicanálise lida com as noções de vulnerabilidade, tão cara às disciplinas sociais.

A descrição, em termos pulsionais, para o que Freud (1950[1895]/1996q), definiu como desamparo, nos levou a aproximar tal noção à de estado de perigo pulsional. A necessidade de se debruçar sobre esta tese originou o trabalho atual no qual buscamos responder sobre o estatuto conceitual do termo desamparo. Nossa hipótese é a de que, se tal estatuto se refere a uma condição de perigo pulsional, e isso requer exploração conceitual e atualização, é coerente tomar tal estatuto como paradigma no diálogo com as ciências sociais, em relação ao que ali se conhece como condição de vulnerabilidade, guardadas, obviamente, suas devidas distinções.

\section{Método}

Para responder a tal questão, realizamos um levantamento de todos os momentos em que o termo aparece na obra freudiana e consolidamos nosso texto a partir do sentido comum que ele ganha em cada passagem. Assim não há, necessariamente, um compromisso em apresentar as passagens do termo na ordem cronológica em que vão se sucedendo na obra, mas sim, a partir de categorias que permitiram extrair, em cada passagem, aquilo que estava em causa para Freud.

Buscamos, com essa metodologia aplicar a análise estrutural desenvolvida por Lacan na análise dos sintomas ao campo conceitual. Lacan (1975/1998) propõe distinguir, apoiado no texto de Freud sobre O sentido dos sintomas (1917[1916-1917]/1996g), duas vertentes do sintoma: a do sentido (Sinn) e a da significação (Beudeutung). Na vertente do sintoma, teríamos uma construção hermenêutica do sentido que subjaz ao texto - no caso de Freud, ao texto do sujeito que fala em análise e, no caso de nosso artigo, ao texto escrito do pai da psicanálise.

Na perspectiva da significação, opera-se com a referência significante e o sentido que dela foge, permitindo que se interprete o mesmo termo a partir de diferentes perspectivas. Essa diferença 
foi extensamente explorada por Frege e traz em seu interior a diferença entre sentido e referente, tomada depois por Lacan como diferença entre o sentido que desliza entre diferentes significados e o que o fixa como elemento real impossível de apreender. Dessa maneira, aplicado o método clínico de interpretação modalizado por essa diferença à metodologia de pesquisa orientada pela psicanálise, propomos decantar do sentido seus pontos de fixação conceituais em Freud, trabalhando a noção de desamparo a partir dessa lógica metodológica.

\section{Resultado}

A revisão da noção de desamparo em Freud nos levou à proposição de três modalizações do termo. Evidenciaremos, agora, a etiologia dessa composição em Freud.

\section{Desamparo estrutural: o Desamparo como ameaça às exigências da vida: alteridade e ação específica}

É no artigo Projeto para uma psicologia científica, de 1950[1895]/1996q, texto inacabado de Freud, que a relação entre desamparo e aquilo que ele chama de "exigências da vida" fica mais clara. A operação denominada de experiência de satisfação depende da presença de uma alteridade, cuja ação em relação ao desamparo é fundamental na satisfação das descargas pulsionais. Trata-se de demandas intensas e exigentes que se originam de estímulos internos, do corpo, ou seja, pulsionais. Deles o organismo não pode fugir, nem evitar, sendo este o motivo que leva o sujeito a buscar no mundo externo as condições adequadas, ou necessárias, para que cessem. É preciso, então, que o organismo empreenda o esforço de sair de sua tendência original à inércia, para tolerar um acúmulo de energia suficiente que possa dirigir, na direção do outro, uma ação específica. Este esforço a mais do organismo resulta na propensão a uma descarga motora que, no caso da criança pequena, conhecemos através do grito, ou do choro intenso. É assim que Freud (1950[1895]/1996q, p. 349) define a experiência de satisfação, ou seja, um mecanismo econômico primordial na constituição psíquica, cuja função é a de manter as funções impostas pelas "exigências da vida."

Certamente, para o sujeito atravessado pela linguagem, a experiência de satisfação de tais "exigências da vida" não há de estar ligada puramente ao campo biológico da necessidade e, ao que nos parece, Freud se dá conta disso muito cedo. É o que vemos no caso de histeria de Emmy Von R, de 1889 (Freud, 1893-1895/1996a). O primeiro texto em que o termo "desamparo" aparece em sua obra. Na linguagem que escapa ao controle do corpo, as gagueiras e tiques nervosos que Emmy sofria foram considerados por Freud como sendo da ordem de uma fórmula protetora. "Fique quieto! Não diga nada! Não me toque!", dizia ela ao sentir-se ameaçada pelas "exigências da vida" que se Ihe impunham. A fórmula deveria protegê-la do curso que seus pensamentos poderiam tomar, do medo da morte que sentia, de ser atacada pelos objetos de suas zoopsias, dos perigos conscienciosos que a sexualidade the trazia, das lembranças de ter sido agarrada por seu irmão, seu primo e sua filha mais 
velha quando os mesmos estavam adoecidos. Intensos estados emocionais também a acometiam, aos quais ela própria denominava de "tempestades na cabeça". Nas ocasiões em que beirava a fadiga com os cuidados que a filha mais velha exigia, já que também sofria "dos nervos", adotava o hábito de chamar pelo nome "Emmy", o mesmo desta filha.

Deste estado caótico que se impunha sobre Emmy extraímos a noção de desamparo que o caso apresenta. Em seu drama familiar, a morte do marido coincidiu com o nascimento da segunda filha, o que a fez rejeitá-la nos três primeiros anos de vida por acreditar que este bebê a impediu de cuidar do marido. A filha mais velha era, claramente, objeto de suas preferências maternas, não por acaso, recebera o mesmo nome da mãe. De modo que chamar pelo nome "Emmy", tinha efeito sobre si mesma, em seu estado de desamparo. "Segundo as normas que regem os ataques histéricos, a exclamação 'Emmy' durante seus acessos de confusão reproduzia, como havemos de recordar, seus frequentes estados de desamparo [grifo nosso] durante o tratamento da filha." (Freud, 18931895/1996a, p. 123,).

A expressão "Emmy!" seria, assim, a maneira que o próprio psiquismo havia encontrado de proteger o sujeito de uma situação ameaçadora. Na ausência de uma alteridade que produzisse uma ação específica, a construção deste sintoma dava tratamento para o estado de desamparo ao qual se encontrava em sua solidão. A noção de desamparo presente no caso Emmy ensina, portanto, que este estado convoca uma ação específica frente a um estado de perigo iminente que ameaça as exigências da vida, cuja satisfação busca objetos naturalizados no campo simbólico, no qual a lógica pulsional opera e constitui a interioridade e a exterioridade que definem a realidade psíquica do sujeito.

No manejo da transferência, Emmy coloca Freud no lugar desta alteridade capaz de the empreender tal ação específica, cujo efeito é o de engajar o sujeito na dialética enigmática do desejo inaugurado pelas exigências da vida. Ao subverter o método hipnótico, Emmy demonstra uma posição ativa nos processos psíquicos dos quais se queixava: "[...] prefiro ter minhas dores!" (Freud, 18931895/1996a, p. 109), verbalizou. Esta posição do sujeito revela de que forma a experiência de satisfação é reativada toda vez que uma descarga pulsional, na busca por uma ação específica, se transforma em demanda, inaugurando o eixo necessidade/demanda/desejo.

Emmy situa Freud na posição de quem deve acolher a demanda que, enquanto tal, precisa ser escutada. "Concordei com isso e ela prosseguiu, sem nenhum preâmbulo" (Freud, 1893-1895/1996a, p. 94). A adoção da associação livre, influenciada pelo tratamento de pacientes como Emmy, sem dúvida, abre caminho para que o analista possa ser colocado no lugar desta alteridade capaz de dirigir, com seu ato e no manejo da transferência, uma ação específica em relação ao desamparo do sujeito.

\section{O Desamparo e certo modo específico de satisfação}


Duas questões se colocam aqui: a alteridade estaria sempre em posição de quem realiza, na experiência de satisfação, uma ação específica que apazigua o desamparo? E outra: haveria modos de satisfação que o próprio sujeito experimentaria mantendo sua condição de desamparado? Em $A$ etiologia da histeria, Freud (1896/1996b), que ainda estava às voltas com sua teoria do trauma na busca por encontrar as causas da neurose, destaca situações em que um adulto toma uma criança como objeto de seu gozo, de sua indiferença, ou, de seu descaso. É quando "(...) de outro lado, a criança, que em seu desamparo [grifo nosso] fica à mercê dessa vontade arbitrária, que é prematuramente despertada para todo tipo de sensibilidade e exposta a toda sorte de desapontamentos (...)" (Freud, 1896/1996b, p. 210) experimentará o desamparo face a certos modos específicos de satisfação.

Em 1913[1912-1913]/1996f, em Totem e Tabu, Freud retoma o tema, no âmbito da cultura, abordando situações em que o estado de desamparo representa uma condição de tabu por nela o sujeito ser objeto de fantasias proibidas. "Homens mortos, recém-nascidos e mulheres menstruadas ou nas dores do parto estimulam desejos pelo seu desamparo [grifo nosso] especial; um homem que acaba de atingir a maturidade os estimula pela promessa de novo prazer" (Freud, 1913[19121913]/1996f, p. 50). A cultura impõe que se resista às tentações as quais um sujeito desamparado evoca, o que se dá através dos deslocamentos das finalidades sexuais das pulsões. No inconsciente, aquilo que é proibido é o que mais se deseja, por isso, requer mecanismos de defesa. Por outro lado, quem viola um tabu, se torna também um tabu porque evidencia a existência do desejo inconsciente que pode estar na base de uma sociedade, tal como a perversão é paradigma. "O fato de um homem morto achar-se em desamparo [grifo nosso] está fadado a atuar como um incentivo a quê o sobrevivente dê rédea livre às suas paixões hostis e essa tentação de ser contraditada por uma proibição" (Freud, 1913[1912-1913]/1996f, p. 75).

Duas dimensões do gozo são encontradas no texto Personagens psicopáticos no palco, no qual Freud (1905-1906/1996e) toma emprestado o modelo do drama para demonstrar que, em sua lógica, este gênero teatral pede uma ação que engendra o sofrimento de quem o assiste e que, enquanto expectador, extrai daí algum prazer, assim como no próprio personagem do desamparo há também um prazer extraído de sua condição. No desenrolar de uma trama dramática a finalidade é despertar "terror e comiseração" (Freud, 1905-1906/1996e, p. 292). James Strachey (Freud, 19051906/1996e, p. 292), lembra em uma nota que, em alemão, comiseração é traduzido pelo termo "mitleid", que significa "sofrimento solidário". No jogo da fantasia, os dilemas que se sucedem permitem "(...) extrair um gozo até de nosso próprio sofrimento" (Freud, 1905-1906/1996e, p. 294). Exemplo disso é "(...) o desamparo [grifo nosso] do doente em Filoctetes ou a desesperança dos enfermos nas peças que giram em torno dos tísicos." (Freud, 1905-1906/1996e, p. 294).

Em Dostoievski e o parricídio (Freud, 1928/1996l), segue na proposição de uma satisfação específica no desamparo ao distinguir a personalidade de Dostoievski em quatro facetas: o artista 
criador, o neurótico, o moralista e o pecador. Discute seu caráter masoquista, o sentimento de culpa que o atormentava, a sexualidade marcada pela masturbação e suas relações edípicas. Em uma carta

a Theodor Reik, apêndice do artigo, cita o termo desamparo para dizer das relações amorosas patologicamente estabelecidas por Dostoievsky. "Considere seu espantoso desamparo [grifo nosso] frente às manifestações do amor" (Freud, 1928/1996l, p. 200).

Fica, assim, evidenciado que a experiência de satisfação não se sustenta por uma perspectiva cartesiana que separa o prazer do desprazer, como se estivessem em lados opostos. Os modos de satisfação podem conhecer diversos caminhos, os mesmos que as vicissitudes pulsionais podem encontrar, especialmente amalgamando prazer e desprazer. Se a experiência de satisfação, tal como propõe Freud (1950[1895]/1996q), inaugura um eixo que transforma necessidade em desejo, através da dialética da demanda submetida às leis simbólicas, tal satisfação não pode encontrar na ação específica uma resposta única, ou, idealizada para o desamparo. As subversões que a pulsão inaugura em sua busca por satisfação estão aí implicadas.

\section{O Desamparo e os perigos pulsionais: um estado infantil}

O modo como Freud (1893-1895/1996a) cita o termo desamparo, no caso de Elizabeth Von N., nos permite introduzir o recorte que destacamos na relação entre esta noção e a particularidade dos perigos aos quais o sujeito da linguagem encontra-se submetido. O que está em causa é o modo que a psicanálise freudiana concebe o infantil como a cena inconsciente atemporal e estrutural para a instauração de uma subjetividade que se constituirá na relação com a alteridade, distinguindo-se aí das perspectivas desenvolvimentistas. Com Lacan, marcaríamos aqui as vicissitudes do gozo advindo do fato de que falar traumatiza e envia o sujeito a uma satisfação singular que escapa à significação e a linguagem. Nesse artigo, entretanto, nos deteremos em Freud a fim de promover um diálogo com o campo das ciências sociais em sua última parte.

Freud (1893-1895/1996a) utiliza o termo desamparo neste caso em dois momentos. No primeiro, quando diante da morte do pai, Elizabeth se sente impulsionada a uma espécie de expectativa nostálgica, própria de um estado infantil: "Nessa oportunidade, Elizabeth sentiu claramente seu desamparo [grifo nosso], sua incapacidade de oferecer à mãe um substituto para a felicidade perdida e a impossibilidade de cumprir seu propósito, assumido quando da morte do pai" (p. 167). Freud (1893-1895/1996a) supõe que Elizabeth ocupava o lugar do filho que o pai não havia tido e, quando este morre, a jovem se encontra amarrada aos compromissos que conscienciosamente assumiu ter junto ao lugar idealizado de suas relações parentais. O segundo momento em que o termo desamparo é abordado no caso de Elizabeth, torna ainda mais evidente sua impossibilidade de sair do lugar que ocupava na vida: "(...) em outra série, que compreendia suas malogradas tentativas de estabelecer uma nova vida familiar, não se cansando de repetir que o doloroso nisso era o 
sentimento de seu desamparo [grifo nosso], a sensação que 'não saia do lugar'"' (Freud, 18931895/1996a, p.167).

A equivalência entre desamparo e estado infantil fica clara quando, alguns anos mais tarde, Freud (1893-1895/1996a, p. 370) escreve sobre a experiência de satisfação, cuja matriz se estabelece na infância, enquanto que suas vicissitudes alcançam o sujeito ao longo da vida, superando a necessidade fisiológica para estabelecer a dialética entre demanda e desejo. Frente a um "estado infantil", no qual uma ação específica se efetua por ajuda de um outro experiente, encontra-se o "desamparado". Ocorre que a dimensão do desamparo, que surge do caso de Elizabeth, nos remete ao que ocorre na impossibilidade de realização desta ação, engendrando, assim, a produção dos sintomas de dores fortes nas pernas e paralisia, que resultariam em sua incapacidade de "sair do lugar", romper certos laços e lugares, mantendo-se presa ao imaginário nostálgico e idealizado de sua infância.

Mas, assim como o tema do desamparo infantil aparece nos primórdios da psicanálise, também está presente no final da obra freudiana, em Análise terminável e interminável de 1937/1996p. "Nessa época, aceitei o caso de um jovem russo, homem estragado pela opulência, que chegou em Viena em estado de completo desamparo [grifo nosso], acompanhado de um médico particular e um assistente." (Freud, 1937/1996p, p. 232). Não por acaso, esse caso, o do Homem dos lobos, foi nomeado de Uma neurose de infância, denotando o uso do termo desamparo como aquele que diz respeito ao desamparo infantil e originário, estruturante do sujeito.

\section{0 desamparo radical: uma "infamiliar" cena infantil: o desamparo e a repetição}

Uma dimensão estranhamente infantil do desamparo se destacou em dois textos em especial. Em 1905/1996d, no texto Os chistes e sua relação com o inconsciente, a referência ao termo desamparo surge como um estado infantil, embaraçoso, que se manifesta através do chiste. Freud (1905/1996d) descreve três possibilidades cômicas nas quais esse estado surge: em comparação com outra pessoa e o eu; por uma comparação inteiramente no interior de outra pessoa e; por uma comparação inteiramente no interior do eu. É quando trata da segunda delas que recorre ao termo desamparo, localizando aí um tipo de chiste em que afirma se comprovar de modo mais eficaz o ponto de vista infantil. "Pois o cômico da situação é maximamente baseado no embaraço, no qual redescobrimos o desamparo [grifo nosso] infantil" (Freud, 1905/1996d, p. 210). O adulto, nesta situação, se reduz a uma criança em seu desamparo e aí está o ponto de embaraço que o leva a uma experiência de degradação.

Seguindo neste mesmo eixo em que uma cena de estranhamento desvela um estado de desamparo infantil, o texto O estranho, de 1919/1996h, nos oferece duas passagens interessantes. $\mathrm{Na}$ primeira, Freud (1919/1996h) fala de um fator de repetição que provoca em algumas pessoas a sensação de estranheza. Essa sensação remete a conteúdos recalcados, já que estes não são 
reconhecidos pela consciência, apenas o afeto que evocam. "Daquilo que tenho observado, sujeito a determinadas condições e combinados a determinadas circunstâncias provoca indubitavelmente uma sensação estranha, que, (...) evoca a sensação de desamparo [grifo nosso] experimentada em alguns estados oníricos" (Freud, 1919/1996h, p. 254).

Na segunda passagem, destaca-se o estranho encontro com o familiar. Freud discorre sobre isso ao analisar sua experiência própria de, ao passear por algumas ruas da Itália, ter tido uma sensação de déjàvu: "Outras situações, que tem em comum com a minha aventura, um retorno involuntário da mesma situação, as quais, porém, dela diferem radicalmente em outros aspectos, resultam também na mesma sensação de desamparo [grifo nosso] e de estranheza." (1919/1996h, p. 254). A clássica frase de Freud: "O estranho provém de algo familiar reprimido" (1919/1996h, p. 254) tem aqui seu lugar. $O$ estranho é o reencontro com o desamparo constitutivo instaurado nas relações do sujeito com o objeto e, por isso, nos é familiar. Nessa vertente, o desamparo na experiência vívida e atual implica uma repetição do desamparo estrutural e infantil, constitutivo, trazendo à tona seu afeto familiar como elemento estranho e, ao mesmo tempo, íntimo. Entendemos que aqui Freud dá início a uma segunda modalização do desamparo psíquico que implica na revivescência da experiência originária de abandono.

\section{A relação de objeto}

No caminho pelo qual traçamos a dimensão infantil do desamparo, em Freud, nos deparamos com a relação de objeto, tal como a encontramos em sua obra. Na terceira parte dos Três ensaios sobre a sexualidade (Freud, 1905/1996c), As transformações da puberdade, na seção $A$ relação de objeto, a noção de desamparo surge articulada ao que resta de mais importante de todos os vínculos sexuais da criança e que prepara a relação de objeto, mesmo depois que tal relação se separa da nutrição. Trata-se de uma dimensão constitutiva da subjetividade e, portanto, da constituição do sujeito que a psicanálise freudiana apresenta. Ela encontra sua radicalidade na passagem adolescente.

Por considerar que, nas relações da criança com aquele que a ajuda em seu desamparo, a criança é o substituto de um objeto sexual, Freud afirma: "Durante todo o período da latência a criança aprende a amar outras pessoas que a ajudam em seu desamparo [grifo nosso] e satisfazem suas necessidades, e o faz segundo o modelo de sua relação de lactente com a ama e dando continuidade a ele." (1905/1996c, p. 210). Em uma nota de rodapé acrescentada em 1915, indica de forma mais clara, dois caminhos para o encontro com o objeto: o primeiro é ressaltado no texto e que se dá por apoio a modelos infantis primitivos, referentes àqueles que cuidaram da criança. É por este caminho que a criança aprende a amar e se torna capaz de realizar em sua vida posterior tudo aquilo que a economia pulsional opera. O segundo se dá pelo modelo narcísico, no qual o próprio ego do 
sujeito é o modelo que vai ser reencontrado posteriormente no outro. Este último com efeitos patológicos.

A via narcísica, pela qual também opera o encontro com o objeto e na qual o desamparo tende a se estabelecer de forma mais radical (Januzzi, 2018; Ferrari, Guerra \& Januzzi, 2020), é retomada em Inibições, sintomas e angústia (Freud, 1926/1996j). Nestas condições, estabelece-se uma impossibilidade da catexia narcísica de se deslocar para a de objeto, resultando, nas palavras de Freud, em um estado de desamparo psíquico. "Quer o ego esteja sofrendo de uma dor que não para ou experimentando um acúmulo de necessidades instintuais que não podem obter satisfação, a situação econômica é a mesma, e o desamparo [grifo nosso] motor do ego encontra expressão no desamparo [grifo nosso] psíquico" (Freud, 1926/1996j, p. 163). Neste texto, o desamparo surge como um sinal de perigo que consiste na perda do objeto e de suas imagos, a quem inicialmente, a criança encontra satisfação para suas necessidades. Esta é a operação que dá origem ao desamparo psíquico, que deriva de uma condição biológica - aspectos que serão melhor desenvolvidos mais adiante. A mesma discussão que articula o desamparo psíquico à perda do objeto pode ainda ser encontrada na Conferência XXXII - Angústia e vida instintual: "O perigo de desamparo [grifo nosso] psíquico ajustase ao estádio da imaturidade inicial do ego; o perigo de perda de um objeto (ou perda do amor) ajusta-se à falta de auto-suficiência dos primeiros anos da infância" (Freud, 1932/1996n, p. 91), assim como, sucessivamente, o perigo da castração e o temor do superego. Na relação com o objeto, o desamparo torna-se parte da constituição estrutural do sujeito, da mesma forma que, nas diversas formas pela qual o objeto pode se ausentar para o sujeito, estão também as bases de um desamparo radical.

\section{Perigos internos, perigos externos e a angústia}

Um bonito exemplo de como, já em 1905/1996c, nos Três ensaios, Freud se dá conta das especificidades dos perigos aos quais o sujeito da linguagem está submetido, nos é dado em uma nota de rodapé em que trata da angústia infantil. Embora, o termo desamparo não apareça no trecho destacado, a angústia aí implicada é emblemática para esta equivalência.

Devo o esclarecimento da origem da angústia infantil a um menino de três anos que certa vez ouvi rogar de um quarto escuro: Titia, fale comigo! Estou com medo porque está muito escuro. $\mathrm{E}$ a tia lhe respondeu: De que lhe adianta isso? Você não pode mesmo me ver! Não faz mal, respondeu o menino. Quando alguém fala fica mais claro!" (Freud, 1905/1996c, p. 212).

A angústia, nessa passagem, sinaliza o vazio que, sem forma, aterroriza, evocando um desamparo radical. $\mathrm{O}$ apelo ao outro vem em socorro. A voz, sem forma, modula o vazio que o objeto 
porta. Na passagem adolescente, o reencontro com esse vazio radical na experiência de si é o que testemunhamos como esse desamparo radical.

A partir de $O$ ego e o id, texto de 1923/1996i, tempo da segunda tópica, o desamparo surge, de forma clara, como um estado que deriva de um fator biológico, mas que encontrará nas vicissitudes do complexo de Édipo, entre outros aspectos, as condições que darão origem ao superego, cuja origem é articulada à duração prolongada da infância. Os conflitos entre o ego e o superego refletirão o contraste em relação àquilo que, neste momento, Freud (1923/1996i) ainda distingue como o real e o psíquico ou o mundo externo e o interno. O superego é o resultado da "(...) duração prolongada, no homem, do desamparo [grifo nosso] e dependência de sua infância, e o fato de seu complexo de Édipo, cuja repressão demonstramos achar-se vinculada à interrupção do desenvolvimento libidinal pelo período de latência (...)" (Freud, 1923/1996i, p. 47). Este fator consiste no longo período da infância em que "(...) o jovem da espécie humana está em condições de desamparo [grifo nosso] e dependência" (1926/1996j, p. 151), no qual está submetido, por questões de sobrevivência fisiológica e afetiva, aos objetos primordiais da infância. É do longo desamparo biológico da criança que se produzirão as condições para que suas necessidades encontrem meios bastante particulares de satisfação na instauração de um tipo muito especial de instinto que se origina do corpo e ultrapassa a condição biológica no caminho que leva à humanização do organismo, isto é, a pulsão. Por isso, Freud distingue as pulsões, do instinto animal. E ainda que as pulsões de vida, aquelas que compreendem as pulsões do eu e de autopreservação visam, sobretudo, a preservação do sujeito, a pulsão de morte visa reduzir a tensão orgânica a um estado inorgânico, o que deixa evidente as relações da pulsão com o corpo e com o mundo externo.

Também não é à toa que a angústia é sentida no corpo e tem no ego a sede que a percebe no nível das sensações, fato que se observa desde os primórdios da psicanálise, quando a angústia esteve associada à descarga somática de uma excitação pulsional insatisfeita ou inadequada. Em Inibições, sintomas e angústia, a angústia é sentida como um sinal que avisa de um perigo desamparador para o sujeito, mas, é também "[...] produto do desamparo [grifo nosso] mental da criança, o qual é um símile natural de seu desamparo [grifo nosso] biológico" (Freud, 1926/1996j, p. 136). Em um movimento que distingue a noção de infância da noção atemporal do inconsciente infantil, Freud começa a equivaler os perigos internos aos perigos externos aos quais o sujeito está submetido na constituição e na sustentação de sua subjetividade.

A equivalência entre desamparo real, ou seja, aquele que vem do mundo externo e aquele que é psíquico e que, portanto, vem do mundo interno, é trabalhada progressivamente. Ao se referir a uma situação traumática, ou seja, um perigo ou um estado de desamparo, Freud diz que "claramente, ela consiste na estimativa do paciente quanto à sua própria força em comparação com a magnitude do perigo e no seu relacionamento de desamparo [grifo nosso] em face deste perigo - desamparo [grifo nosso] físico se o perigo for real e psíquico se for pulsional" (Freud, 1926/1996j, p. 161). Em 
seguida, faz uma distinção entre o que chama de angústia realística e angústia neurótica. Embora na primeira, o perigo é conhecido e na segunda, não, a análise revela que o perigo de que se trata é pulsional, já que a produção de um sinal de angústia implica na instauração da dimensão simbólica da linguagem. A função da angústia é, assim, a de proteger o ego da situação pulsional traumática.

"Denominemos uma situação de desamparo [grifo nosso], que ele realmente tenha experimentado, de 'situação traumática'. Teremos então bons motivos para distinguir uma situação traumática de uma situação de perigo" (Freud, 1926/1996j, p. 161). Assim, o desamparo é produto de uma situação traumática e, portanto, geradora de angústia. A situação de perigo se define por remeter o sujeito aos resquícios da situação traumática. Neste contexto, quando um sinal de angústia é emitido, o "(...) sinal enuncia: 'estou esperando que uma situação de desamparo [grifo nosso] sobrevenha' ou 'A presente situação me faz lembrar uma das experiências traumáticas que tive antes" (Freud, 1926/1996j, p. 161). Assim, a angústia comporta dois aspectos: a expectativa do trauma e sua repetição de forma atenuada, além de colocar o ego em posição ativa frente ao trauma na tentativa de dirigir seu próprio curso.

Assim, o perigo externo é internalizado por ter sido significativo para o ego, sendo também relacionado com certa situação de desamparo, de tal forma que, na situação traumática convergem-se perigos reais e instintuais. "Sua vinculação com a expectativa pertence à situação de perigo, ao passo que sua indefinição e falta de objeto pertencem à situação traumática de desamparo [grifo nosso] - a situação que é prevista na situação de perigo (perigo externo)" (Freud, 1926/1996j, p. 162). A situação traumática supõe a perda de objeto e a situação de perigo implica em reviver esta perda. 0 perigo externo, "(...) estimula o indivíduo a permanecer no estado de infância, cujo período de vida se caracteriza pelo desamparo [grifo nosso] motor e psíquico (...)" (Freud, 1926/1996j, p. 162), sendo daí que se pode apreender a noção de desamparo infantil.

Apesar de, inicialmente, Freud (1926/1996j) fazer distinção entre o que chamou de angústia realística e a neurótica, verificamos que ele acaba por concluir: "Até agora não tivemos oportunidade alguma de considerar a angústia realística sob qualquer luz diferente da angústia neurótica." (p.162). Se um perigo real é aquele que ameaça uma pessoa a partir de um objeto externo e um perigo pulsional é aquele que o ameaça a partir de uma exigência pulsional, na verdade, em "(...) relação à situação traumática, na qual o paciente está desamparado [grifo nosso], convergem perigos externos e internos, perigos reais e exigências instintuais" (Freud, 1926/1996j, p.163), de tal maneira que a angústia realística e a neurótica são parte do mesmo processo.

Lacan, nos anos 1950, formaliza essa ideia com o aforismo "o inconsciente é estruturado como uma linguagem" e, nos anos 1960, com a topologia das superfícies, como a banda de moebius, o cross-cap ou a garrafa de Klein, indicando uma continuidade entre mundo externo e mundo interno. O que em Freud ganha forma através da discussão acerca da pulsão: "Chegamos também à conclusão de que uma exigência pulsional só se torna um perigo (interno) porque uma satisfação provocaria um 
perigo externo - isto é, porque o perigo interno representa um perigo externo" (Freud, 1926/1996j, p.163).

Na série que articula a situação de perigo, "(...) angústia - perigo - desamparo [grifo nosso] (trauma)" (Freud, 1926/1996j, p. 162) se perfilam, de modo que, na explicação freudiana, uma "(...) situação de perigo é uma situação reconhecida, lembrada e esperada de desamparo [grifo nosso]. A angústia é a reação original ao desamparo [grifo nosso] no trauma, sendo reproduzida depois da situação de perigo como um sinal em busca de ajuda." (Freud, 1926/1996j, p. 162). A expectativa do desamparo é a situação de perigo, cujo sinal, é produzido pela angústia.

\section{O desamparo generalizado: o mal estar do desamparo e a religião}

Na parte III de O futuro de uma ilusão, em 1927/1996k, o desamparo emerge como aquilo que dá a real clareza da condição de fraqueza e insignificância humana frente ao poder da natureza. "É com essas forças que a natureza se ergue contra nós, majestosa, cruel e inexorável; uma vez mais nos traz a mente nossa fraqueza e desamparo [grifo nosso], de que pensávamos ter fugido através do trabalho da civilização" (Freud, 1927/1996k, p. 25). Freud a associa ao desamparo infantil naquilo em que o diferencia da própria referência estritamente etária da infância: "Já uma vez mais, nos encontramos em semelhante estado de desamparo [grifo nosso]; como crianças de tenra idade, em relação a nossos pais" (Freud, 1927/1996k, p. 26).

Freud destaca que em nossa cultura as figuras parentais, em especial o pai, é aquele ou são aqueles a quem se teme, mas também a quem se espera proteção contra os perigos da vida. Esses perigos remetem o sujeito a um estado infantil aos quais as contingências da vida o conduzem em diversos outros momentos da vida adulta. Assim, mesmo adulto, o sujeito se vê desprotegido, abandonado, negligenciado. A religião testemunha a busca por proteção face a essa generalização do desamparo. O homem adulto, civilizado, pode buscar proteção em figuras divinas parentais, como uma mãe de amor, um irmão fraterno, um pai todo poderoso... "O desamparo [grifo nosso] do homem, porém, permanece e, junto com ele, seu anseio pelo pai e pelos deuses" (Freud, $1927 / 1996 k$, p. 26). Em momentos remotos, as forças da natureza também foram imbuídas de poderes divinos, como se encarnassem entidades divinas. Assim, as forças da natureza, os deuses e o pai, convertem-se em recursos a quem o homem, em seu desamparo, busca proteção.

Como recurso capaz de lidar com uma herança filogenética e ontogenética da fragilização humana, a religião, assim como tantas outras facetas da civilização, surge em resposta ao desamparo do homem. "Foi assim que se criou um cabedal de ideias, nascido da necessidade que tem o homem de tornar tolerável seu desamparo [grifo nosso], e construído com o material das lembranças do desamparo [grifo nosso] de sua própria infância e da infância da raça humana" (Freud, 1927/1996k, p. 27). Através de um recurso literário, Freud promove um diálogo argumentativo consigo mesmo para validar seus argumentos de que o complexo paterno do homem adulto é paradigmático das 
experiências de desamparo infantil. Assim, frente a esse desamparo, o homem humaniza sua dimensão natural através de um campo simbólico. "Você argumenta que a humanização da natureza deriva da necessidade de pôr fim à perplexidade e ao desamparo [grifo nosso] do homem frente a suas forças temíveis, de entrar em relação com elas e, finalmente, de influenciá-las" (Freud, $1927 / 1996 k$, p. 30). Freud tenta atribuir o valor das ideias religiosas ao desamparo físico e psíquico do homem. "Você descobriu o fator da fraqueza e do desamparo [grifo nosso] humanos, ao qual, na verdade, o principal papel, na formação da religião é geralmente atribuído, e agora transpõe tudo que foi outrora o complexo paterno em função do desamparo [grifo nosso]" (Freud, 1927/1996k, p. 31). A relação entre o desamparo da criança, o desamparo do adulto e a necessidade de proteção que o homem encontra na religião é, então, justificada. Estão aí, os motivos manifestos "(...) entre o complexo paterno e o desamparo [grifo nosso] e a necessidade de proteção do homem. (...) Os motivos para a formação da religião que a psicanálise revela agora, mostram ser os mesmos que a contribuição infantil aos motivos manifestos" (Freud, 1927/1996k, p. 32).

A religião surge como forma, na civilização, de reagir ao desamparo infantil que se prolonga e se generaliza no adulto. "É a defesa contra o desamparo [grifo nosso] infantil que empresta suas feições características à reação do adulto ao desamparo [grifo nosso] que ele tem de reconhecer reação que é exatamente, a formação da religião" (Freud, 1927/1996k, 1996, p. 33). Na sexta parte do texto Freud acentua que a necessidade de proteção da infância desperta a proteção através do amor, inicialmente, proporcionada pelos pais. Com "(...) o reconhecimento de que esse desamparo [grifo nosso] perdura através da vida, tornou-se necessário aferrar-se à existência de um pai, dessa vez, porém, um pai mais poderoso." (Freud, 1927/1996k, p. 39).

\section{O desamparo generalizado no mal-estar da civilização:}

Na última citação em que o termo desamparo aparece no texto sobre a religião, ele ganha um acento mais generalizado. Freud destaca a insignificância do homem frente ao universo, demonstrando como isso toca a humanidade narcisicamente frente à necessidade de uma proteção infantil. "Terão de admitir para si mesmos toda a extensão de seu desamparo [grifo nosso] e insignificância na maquinaria do universo, (...)" (Freud, 1927/1996k, p. 57).

Nessa perspectiva ampliada, em O mal estar na civilização (Freud, 1930[1929]/1996m), o termo surge novamente como uma reafirmação do texto. "A derivação das necessidades religiosas, a partir do desamparo [grifo nosso] do bebê e do anseio pelo pai que aquela necessidade desperta, parece-me incontrovertível (...)" (Freud, 1930[1929]/1996m, p. 80). Freud discorda do sentimento oceânico como explicação para o desamparo no homem, já que para ele tudo se passa na dimensão da cena infantil. "A origem da atitude religiosa pode ser remontada, em linhas muito claras, até o sentimento de desamparo [grifo nosso] infantil" (Freud, 1930[1929]/1996m, p. 81). O medo da perda do amor de quem se é dependente leva o sujeito a ficar exposto a perigos devastadores. Esse é, 
portanto, o protótipo da desproteção humana. "Esse motivo é facilmente descoberto no desamparo [grifo nosso] e na dependência dele em relação a outras pessoas e pode ser mais bem designado como medo da perda de amor" (Freud, 1930[1929]/1996m, p. 128). O desamparo e suas relações com o complexo paterno ainda são abordados em um último texto, Conferência XXXV - A questão de uma Weltanschauung (Freud, 1932/19960). "A última contribuição à crítica de Weltanschauung religiosa foi feita pela psicanálise, ao mostrar como a religião se originou a partir do desamparo [grifo nosso] da criança, e ao atribuir seu conteúdo à sobrevivência, na idade madura, de desejos e necessidades da infância" (Freud, 1932/1996o, p. 163).

Como se vê, Freud trabalha a dimensão do desamparo como generalizada na experiência civilizatória, sendo matriz do afeto que busca proteção e enseja a dependência. E por fim, resta ainda uma última citação, embora a mesma não acrescente nenhum ponto novo ao que foi discutido. Ao que podemos destacar que o desamparo do sujeito, quando vertido ao laço social, expandirá a matriz daquilo que resta como infantil na experiência de prazer-desprazer. Não se trata de pensar que o adulto está regredido à posição da criança, mas de decantar que, mesmo no laço social, haverá sempre um movimento pulsional - infantil - de adesão, cuja tendência é a da alienação ao que se oferece com a ilusão de proteção. Essa matriz é o desamparo da própria condição humana, o desamparo infantil, pulsional, radicalizado na experiência adolescente e reencontrado na angústia produzida pelo laço social.

\section{Discussão: as vulnerabilidades do sujeito e a Assistência Social}

Três categorias ordenadoras, extraídas ao longo do percurso consolidado até aqui, orientaram nossas elaborações em torno do estatuto do termo desamparo, em Freud. São elas: desamparo estrutural, desamparo radical e desamparo generalizado. No primeiro plano, aquilo que é da ordem da vulnerabilidade de que se trata quanto ao sujeito da linguagem só pode se inscrever na dimensão simbólica que opera sua subjetividade. Obviamente existem situações limites que situam a sobrevivência de um corpo/organismo e de um corpo/subjetivado, mas, ainda assim, no que tange ao sujeito da linguagem, o que a psicanálise ensina, é que não se trata meramente de ter fome, mas, de ter fome de quê? É aí que se situa o perigo do qual este sujeito está submetido, o de não ser, ou, não encontrar o objeto substituto, parcial, que garanta as exigências da vida pulsional. E, tal objeto só pode ser buscado na relação com o que Lacan (1954/1985a) chamou de Outro.

No segundo recorte, vimos que a experiência do corpo sexuado reedita o desamparo originário e exige novas fontes e novas satisfações, colocando o sujeito face a uma radicalidade de desamparo na relação com o Outro. Este recorte, nos leva a considerar uma dimensão subversiva do desamparo. 0 estado de desamparo do sujeito, naquilo em que reedita a experiência de satisfação, comporta modos arbitrários de realização da economia pulsional e isso também tem efeitos na cultura e na sociedade. Se é possível considerar situações em que, ora o sujeito desamparado é objeto de 
gozo do Outro, ora o sujeito goza do desamparo do outro, não podemos estar desavisados da dimensão que já está em Freud, mas, é particularmente desenvolvida por Lacan (1972/1985b), e que se refere à dimensão gozosa dos modos de satisfação do sujeito. Se há satisfação para o sujeito desamparado, como ensina a histeria, é na posição de vítima ativa que adota ser, frente a seu sofrimento. E, da mesma forma, tomar o desamparado como objeto de certas ações de cuidado, também causa no outro a satisfação pulsional que encontra caminhos contornados na ordem social, por ações segregadoras.

No terceiro recorte, na relação com o Outro, em especial no laço social, demarca-se para o sujeito o desejo de inserção, fundante do ser falante (Miller, 2009, p.6). Ocorre que este lugar, este desejo, não está de antemão, garantido. O sujeito precisará encontrar recursos para sustentá-lo. Quando algo falha nesta operação em que o sujeito busca um lugar no campo do Outro, ele se encontrará em dificuldades com o seu desejo, e é o desamparo, como estado infantil que se apresentará. Assim, a promessa de amparo e proteção, que emerge junto à sociedade moderna, é desconstruída por Freud (1927/1996k;1930[1929]/1996m) em sua crítica sobre o mal estar a que o sujeito se encontra, também na cultura. A fragilidade e, por que não dizer, a vulnerabilidade do sujeito frente à natureza, a finitude da vida e as relações humanas, às condições desiguais de vida, evidenciam a presença do desamparo, sobretudo, em sua vertente de revivescência infantil. A busca por figuras e instâncias superiores, divinas, onipotentes, a identificação com elas pela via totêmica, os avanços da ciência, as substâncias intoxicantes que visam aliviar o sofrimento, nada disso, apaga do sujeito, seu desamparo infantil. Daí a complexidade inerente às ações de auxílio social.

A mesma proteção que, um dia, o sujeito acreditou encontrar nas suas primeiras relações de objeto estão assim, presentes neste "(...) desamparo inicial dos seres humanos (...) fonte primordial de todos os motivos morais" (Freud, 1950[1895]/1996q, p. 370). E aqui, não é insignificante o fato de que o sujeito, por sua condição biológica e psíquica, é o único ser que se dá conta deste nível de vulnerabilidade. Pois, ela só aparece na relação com o Outro. Em outras palavras, a ação social que não considera, além das condições socioeconômicas desiguais, a vertente pulsional do desamparo e o modo como ela molda vias de obtenção de satisfação, tenderá a vitimizar e alienar o sujeito. Aqui a psicanálise dialoga com o campo da assistência social e, como defende Bronzo (2008), faz sua colaboração e aposta numa prática social emancipatória e singularizada que, reconhece a desigualdade social, mas também a capacidade de resposta do sujeito. $\mathrm{O}$ aparato cultural, que também se instaura e se reproduz nas relações de poder, define lugares e hierarquiza papeis que mantém, no ordenamento social, os desamparados socialmente constituídos numa posição que bem pode ser imobilizada pulsionalmente. Assim, evitam-se movimentos sociais de reinvindicação e transformação e se mantém inalteradas as vias de satisfação singulares e as vias econômicas de concentração de riquezas. 
A vulnerabilidade do sujeito, seja na trama do Outro social, parental ou institucional, comporta assim uma dimensão que se estabelece na relação com um Outro desamparador, nas condições em que o sujeito não encontra lugar no seu desejo, mas apenas no lugar de objeto de seu gozo. A discussão contemporânea da necropolítica (Mbembe, 2018; Butler, 2015) dá contorno e forma a esse modelo societário. Ela implica num paradigma que decide fazer morrer face ao capricho neoliberal de tudo objetalizar. Portanto, considerar a dimensão pulsional do desamparo colabora com a construção de novos desenhos políticos que possam denunciar, combater e mesmo buscar reverter esse modo de agenciamento contemporânea da morte.

\section{Conclusões}

A análise psicanalítica da qual extraímos um estatuto para o termo desamparo em Freud, mostrou ser possível o diálogo interdisciplinar com o paradigma da vulnerabilidade, junto às ciências sociais. O social, para a psicanálise, requer a noção de Outro. Lugar da palavra, da linguagem, da cultura e das determinações do sujeito, no Outro o "[...] o social é radical, é a raiz" (Miller, 2009, p. 6). É no campo do Outro que o sujeito busca o objeto da satisfação de seu desejo, deparando-se com a frustração de jamais encontrá-lo. É também aí que se situa a relação de dependência do sujeito ao Outro, pois, o desejo do sujeito está conformado à demanda do Outro, como escreve Miller (2010). O Outro articula a dimensão do desejo, mas só pode dar ao sujeito objetos substitutos de sua realização. E o que deseja o sujeito? Na verdade, aquilo que o situa na vida, ou seja, encontrar um lugar no desejo do Outro. E, mesmo que daí o sujeito só encontre objetos substitutos de sua realização, é na claudicância desta operação que o sujeito se constitui e se sustenta no laço social.

Na emergência de sua subjetividade o sujeito se aliena e se separa do campo do Outro, recusa, recalca ou forclui o significante ordenador deste campo, experimenta a frustração, a privação e a castração neste campo, eminentemente, simbólico. Obviamente, Real e Imaginário também estão aí intrincados, de modo que, para o ser atravessado pela linguagem, as ameaças às exigências da vida, não podem ser puramente da ordem biológica da necessidade, tão pouco, puramente da ordem coletiva do social. É de uma extimidade que se trata, uma íntima relação com o exterior. Assim, o desamparo de que se trata para esse sujeito da linguagem é o desamparo do Outro.

Seja o Outro materno, ou paterno, que negligenciou o amor e os cuidados do sujeito, seja o Outro social que abandonou o sujeito à margem da sociedade, o Outro das políticas públicas que o mantém invisível às suas ações, ou mesmo ao Outro das divindades que não ampara o sujeito em seu sofrimento, o sujeito, ser de linguagem, sofre por se dar conta disso. Daí se pode apreender que, as respostas do sujeito frente ao desamparo, também se revelam em tentativas de regular, eliminar, controlar, ou mesmo, prescindir deste Outro. O estatuto do desamparo em Freud é, neste sentido, pulsional e intrinsecamente articulado ao campo do Outro, evidenciando assim, a importância no tecido social das políticas públicas, de ações capazes de re-conhecer o sujeito enquanto tal. 


\section{Notas:}

1. Pesquisa iniciada em 2018 e, em andamento, inserida no bojo das pesquisas desenvolvidas no núcleo de Psicanálise e Laço Social no Contemporâneo, (PSILACS), no departamento de Psicologia da UFMG, que visa responder à seguinte questão: a categoria do desamparo pode orientar a construção de ações específicas de cuidado nas intervenções psicossociais, especialmente com adolescentes em situação de vulnerabilidade? CAAE: 96236718.3.0000.5149.

2. 'Em seu famoso artigo 'Über Sinn und Bedeutung' ('On Sense and Reference', 1892), Frege contrastou o sentido (Sinn) de uma expressão com sua referência (Bedeutung). Duas expressões podem ter a mesma referência, mas apresentam-na de maneiras diferentes, e este modo de apresentação é o sentido da expressão. Assim, 'George Eliot' e 'Mary Anne Evans' referem-se à mesma pessoa, mas pode ser uma surpresa para alguém saber que a pessoa que conhece como uma é a mesma pessoa que conhece como a outra. Isso, segundo Frege, ocorre porque os termos estão associados a diferentes modos de apresentação de uma pessoa. É o sentido das expressões que determina o pensamento expresso por uma frase em que ocorrem, enquanto a referência determina sua verdade ou falsidade. No entanto, existem frases em que o próprio modo de apresentação ou sentido passa a fazer parte do tópico, caso em que o valor de verdade pode mudar por meio da substituição de termos que, no entanto, têm a mesma referência. Esses contextos são chamados de oblíquos, indiretos ou intensionais (ver extensão / intensão). Duas condições sobre a noção de sentido são que, se duas expressões compartilham o mesmo sentido, não deve ser possível deixar de perceber que compartilham a mesma referência; também os sentidos devem ser públicos e objetivos, como os pensamentos o são para Frege. É difícil identificar uma concepção de sentido que satisfaça ambas as condições. $O$ uso de uma teoria semântica de duas partes deste tipo foi atacado por Russell em seu artigo 'On Denoting' (1905), mas as teorias do significado são comumente baseadas em alguma versão da distinção" (Tradução nossa). Recuperado em 23 de Outubro de

em:

<https://www.oxfordreference.com/view/10.1093/oi/authority.20110803100508390>.

original: "In his famous paper 'Über Sinn und Bedeutung' ('On Sense and Reference', 1892), Frege contrasted the sense (Sinn) of an expression with its reference (Bedeutung). Two expressions might have the same reference, but present it in different ways, and this mode of presentation is the sense of the expression. Thus 'George Eliot' and 'Mary Anne Evans' refer to the same person, but it might come as a surprise to someone to learn that the person he knows as one is the person he knows as the other. This, according to Frege, is because the terms are associated with different modes of presentation of the one person. It is the sense of 
expressions that determine the thought expressed by a sentence in which they occur, whilst reference determines its truth or falsity. However, there are sentences in which the mode of presentation or sense itself becomes part of the topic, in which case truth-value can shift through substitution of terms that nevertheless have the same reference. Such contexts are called oblique, or indirect, or intentional (see extension/intension). Two conditions on the notion of sense are that if two expressions share the same sense it should not be possible to fail to realize that they share the same reference; also senses are to be public and objective, as thoughts are for Frege. It has proven hard to identify a conception of sense that satisfies both these conditions. The use of a two-part semantic theory of this kind was attacked by Russell in his paper 'On Denoting' (1905), but theories of meaning are commonly based upon some version of the distinction". Recuperado em 23 de Outubro de 2020 em: <https://www.oxfordreference.com/view/10.1093/oi/authority.20110803100508390>.

\section{Referências Bibiográficas:}

Bronzo, C. (2008, setembro). Vulnerabilidade, empoderamento e proteção social. Reflexões a partir de experiências latinoamericanas. XXXII Encontro da ANPAD. Rio de Janeiro. Recuperado de http://www. anpad.org.br/admin/pdf/APS-B967.pdf.

Butler, J. (2015). Quadros de guerra: quando a vida é passível de luto? (S. T. M. Lamarão \& A. M. Cunha, Trads.) Rio de Janeiro: Civilização Brasileira.

Ferrari, I. F., Januzzi, M. E. da S., \& Guerra, A. M. C. (2020, outubro 30). Pandemia, necropolítica e o real do desamparo. Revista Latinoamericana de Psicopatologia Fundamental, 23(3), 564582.https://doi.org/10.1590/1415-4714.2020v23n3p564.8 Recuperado de https://www.scielo.br/scielo.php?pid=S1415-47142020000300564\&script=sci arttext\&tlng=pt

Freud, S. (1996a). Estudos sobre histeria. In J. Salomão (Trad.). Edição Standard Brasileira das Obras Psicológicas Completas de Sigmund Freud (vol. 2, pp.13-268). Rio de Janeiro: Imago. (Originalmente publicado em 1893-1895).

Freud, S. (1996b). A etiologia da histeria. In J. Salomão (Trad.). Edição Standard Brasileira das Obras Psicológicas Completas de Sigmund Freud (vol. 3, pp.187-215). Rio de Janeiro: Imago. (Originalmente publicado em 1896).

Freud, S. (1996c). Três ensaios sobre a teoria da sexualidade. In J. Salomão (Trad.). Edição Standard Brasileira das Obras Psicológicas Completas de Sigmund Freud (vol. 7, pp.119-231). Rio de Janeiro: Imago. (Originalmente publicado em 1905).

Freud, S. (1996d). Os chistes e suas relações com o inconsciente. In J. Salomão (Trad.). Edição Standard Brasileira das Obras Psicológicas Completas de Sigmund Freud (vol. 8, pp. 11-219). Rio de Janeiro: Imago. (Originalmente publicado em 1905). 
Freud, S. (1996e). Personagens psicopáticos no palco. In J. Salomão (Trad.). Edição Standard Brasileira das Obras Psicológicas Completas de Sigmund Freud (vol. 7, pp.289-297). Rio de Janeiro: Imago. (Originalmente publicado em 1905-1906).

Freud. S. (1996f). Totem e tabu. In J. Salomão (Trad.). Edição Standard brasileira das obras completas de Sigmund Freud. (vol 13, pp. 117-162) Rio de Janeiro: Imago. (Originalmente publicado em 1913[1912-1913]).

Freud, S. (1996g). O sentido dos sintomas. In J. Salomão (Trad.). Edição Standard Brasileira das Obras Psicológicas Completas de Sigmund Freud (vol. 16, pp. 265-279). Rio de Janeiro: Imago. (Originalmente publicado em 1917[1916-1917]).

Freud, S. (1996h). O estranho. In J. Salomão (Trad.). Edição Standard Brasileira das Obras Psicológicas Completas de Sigmund Freud (vol. 17, pp. 235-269). Rio de Janeiro: Imago. (Originalmente publicado em 1919).

Freud, S. (1996i). O ego e o id. In J. Salomão (Trad.). Edição Standard Brasileira das Obras Psicológicas Completas de Sigmund Freud (vol. 19, pp. 15-80). Rio de Janeiro: Imago. (Originalmente publicado em 1923).

Freud, S. (1996j). Inibições, sintomas e angústia. In J. Salomão (Trad.). Edição Standard Brasileira das Obras Psicológicas Completas de Sigmund Freud (vol.20, pp.81-171). Rio de Janeiro: Imago. (Originalmente publicado em 1926).

Freud, S. (1996k). O futuro de uma ilusão. In J. Salomão (Trad.). Edição Standard Brasileira das Obras Psicológicas Completas de Sigmund Freud (vol.21, pp.67-148). Rio de Janeiro: Imago. (Originalmente publicado em 1927).

Freud, S. (1996l). Dostoievski e o parricídio. In J. Salomão (Trad.). Edição Standard Brasileira das Obras Psicológicas Completas de Sigmund Freud (vol.21, pp.183-200). Rio de Janeiro: Imago. (Originalmente publicado em 1928).

Freud, S. (1996m). Mal-estar na civilização. In J. Salomão (Trad.). Edição Standard Brasileira das Obras Psicológicas Completas de Sigmund Freud (vol.21, pp. 67-148). Rio de Janeiro: Imago. (Originalmente publicado em 1930[1929]).

Freud, S. (1996n). Conferência XXXII - Angústia e vida instintual. In J. Salomão (Trad.). Edição Standard Brasileira das Obras Psicológicas Completas de Sigmund Freud (vol.22, pp. 85-112). Rio de Janeiro: Imago. (Originalmente publicado em 1932).

Freud, S. (19960). Conferência XXXV - A questão de uma Weltanschauung. In J. Salomão (Trad.). Edição Standard Brasileira das Obras Psicológicas Completas de Sigmund Freud (vol.22, pp. 155-177). Rio de Janeiro: Imago. (Originalmente publicado em 1932).

Freud, S. (1996p). Análise terminável e interminável. In J. Salomão (Trad.). Edição Standard Brasileira das Obras Psicológicas Completas de Sigmund Freud (vol.23, pp. 231-270). Rio de Janeiro: Imago. (Originalmente publicado em 1937). 
Freud, S. (1996q). Projeto para uma psicologia científica. In J. Salomão (Trad.). Edição Standard Brasileira das Obras Psicológicas Completas de Sigmund Freud (vol. 1, pp. 335-443). Rio de Janeiro: Imago. (Originalmente publicado em 1950[1895]).

Januzzi, M. E. da S. (2018). Adolescentes usuários de drogas: dificuldades de adesão ao tratamento nos CAPSi. (Tese de Doutorado). Programa de Pós-Graduação em Psicologia. Pontifícia Universidade Católica de Minas Gerais - PUC-Minas, Belo Horizonte, BH, Brasil.

Lacan, J. (1985a). O seminário, livro 2: O eu na teoria de Freud e na técnica da psicanálise. Rio de Janeiro: Zahar. (Trabalho original publicado em 1954-1955).

Lacan, J. (1985b). O Seminário 20: mais, ainda. Rio de Janeiro: Jorge Zahar Editor. (Trabalho original publicado em 1972).

Lacan, J. (1998). Conferência em Genebra sobre o sintoma. In Opção Lacaniana - Revista Brasileira Internacional de Psicanálise, (23), 10. São Paulo: Edições Eolia. (Trabalho original publicado em 1978).

Mbembe, A. (2018). Necropolítica: biopoder, soberania, estado de exceção, política da morte. (R. Santini, Trad.) São Paulo: $n-1$ edições.

Miller, J-A. (2009, maio). Sobre o desejo de inserção e outros temas I. Correio - Revista da Escola Brasileira de Psicanálise, (62), 5-17.

Miller, J-A. (2010). El Otro que no existe y sus comités de ética. 1. Ed. Buenos Aires: Paidós.

Citação/Citation: Máris Campos Guerra, A., Eulália da Silva Januzzi, M.. (mai. 2020 a out. 2020). Vulnerabilidade social e as modalidades do desamparo em Freud: desamparo estrutural, radical e generalizado. Revista aSEPHallus de Orientação Lacaniana, 15(30), 80-100. Disponível em www.isepol.com/asephallus. Doi: 10.17852/1809-709x.2020v15n30p80-100

Editor do artigo: Tania Coelho dos Santos.

Recebido/Received: 04/03/2020 / 03/04/2020.

Aceito/Accepted: 04/20/2020 / 20/04/2020.

Copyright: (c) 2019 Associação Núcleo Sephora de Pesquisa sobre o moderno e o contemporâneo. Este é um artigo de livre acesso, que permite uso irrestrito, distribuição e reprodução em qualquer meio, desde que o autor e a fonte sejam citados/This is an open-access article, which permites unrestricted use, distribution, and reproduction in any medium, provided the author and source are credited. 